\title{
HOW TO RECYCLE A MISUSED LEFT INTERNAL THORACIC ARTERY: TIPS AND TRICKS
}

monica contino ${ }^{1}$, Massimo Lemma ${ }^{2}$, andrea mangini ${ }^{1}$, claudia romagnoni ${ }^{1}$, Paolo Vanelli ${ }^{1}$, and Carlo Antona ${ }^{3}$

${ }^{1}$ ASST Fatebenefratelli Sacco

${ }^{2}$ Jilin University

${ }^{3}$ Università degli Studi di Milano

April 28, 2021

\begin{abstract}
In this case report we describe how to recycle the Left Internal Thoracic Artery (LITA) when misused but not damaged. 8 years after a Left Anterior Small Thoracotomy followed by LAD stenting for STEMI in 1st post-operative day, a 67 years old woman had a NSTEMI with angiographic evidence of intra-stent re-stenosis with a perfectly patent LITA, harvested only from the 4 th to the 6 th intercostal space. During redo surgery, LITA was harvested as a pedicle from the anastomosis to the 4th intercostal space and primarily from the 1 st to the 4 th intercostal space. Special attention was paid at the level of the 4 th intercostal space where the vessel was stuck to the sternum: a 15 blade was used being scissors or cautery too dangerous. At the end of harvesting, the LITA was full-length available for a new coronary anastomosis on LAD, distal to the previous one.
\end{abstract}

\section{Hosted file}

TextCaldara-JCS.pdf available at https://authorea.com/users/410578/articles/519899-how-torecycle-a-misused-left-internal-thoracic-artery-tips-and-tricks 


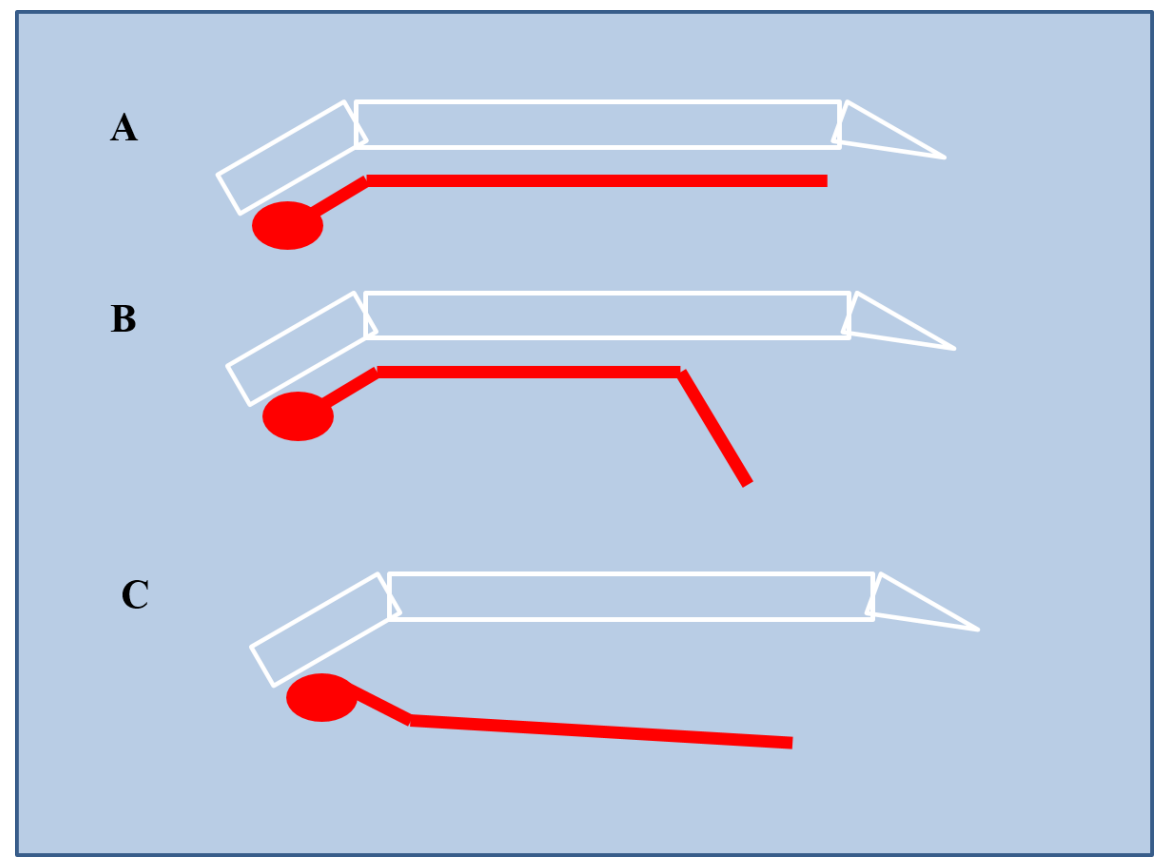

